\title{
DIE PAN-AFRIKANISTIESE VETE TEEN SUID-AFRIKA
}

Die Pan-Afrikanisme het sy oorsprong onder die nakomelinge van die Negerslawe in die Wes-Indiese Eilande en die V.S.A. aan die begin van die huidige eeu. Aanvanklik was die hoofoogmerk die bestryding van diskriminasie teen die Negers in Amerika en die samesnoering van alle Negers in die wêreld in een beweging. Tydens en na die twee wêreldoorloë verskuif die swaartepunt van die beweging na Afrika self en word dit die mondstuk van die nuwe opkomende swart nasionalisme wat veral gedra en gepropageer is deur 'n nuwe intellektuele elite opgelei in Europa en Amerika. Die hoofdoelstellings word van toe af die emansipasie en die eenheid van Afrika.

\section{Die emansipasie van Afrika}

Die wêreldomstandighede geskep tydens en deur die tuee wêreldoorloë het baie bygedra tot die bevordering van die Pan-Afrikanisme en die toestande na die Tweede Wêreldoorlog het die wêreldklimaat geskep vir die asemberowende snelheid waarmee die politieke emansipasie van die grootste gedeelte van Afrika plaasgevind het. In die naoorlogse politieke ontwikkeling het die twee botsende wêreldmoondhede, Rusland en Amerika, beide die anti-kolonialisme as kreet en instrument in die Koue Oorlog aangegryp om die steun te verwerf van die opstuwende nasionalisme en onafhanklikheidsdrang van die mense in Asië en Afrika. Daarby het gekom die verbasende reaksie in Europa self teen wat vertolk is as die rasse-opvattinge van die Nasionaal-Sosialisme en die Fascisme. 'n Diep skuldgevoel teenoor die swart en gekleurde rasse, wat hoegenaamd geen rekening hou met die werklikheid nie, het hom meester gemaak van die Europese mens, en die twyfel en onsekerheid hierdeur geskep, het die koloniale moondhede uiters ontvanklik en kwesbaar gemaak vir die propaganda van die anti-kolonialisme - 'n propaganda wat met krag gevoer is deur die Kommunisme en veral die neo-liberalisme, wat 'n wydverspreide en stewige houvas verkry het op so te sê alle kanale waardeur die openbare mening be- 
invloed en gevorm word: die pers, die raclio en beeldradio, die skole en universiteite, selfs die kerk. Onder hierdie omstandighede was dit vir die groot koloniale moondhede, deur die oorlog verarm en verwar, en in die naoorlogse jare polities en ekonomies grotendeels afhanklik van dic V.S.A., haas onmoontlik om die druk te weerstaan van veral hierdie land om hulle kolonies so gou moontlik - en dikwels met onbesonne haas - vry te maak.

Van hierdie wêreldomstandighede het die swart nasionalisme op behendige wyse gebruik gemaak, met die bekende gevolge. Met die uitsondering van 'n paar kleinere geweste in die noordweste en noordooste van die kontinent het net 'n aantal lande in Suidelike Afrika voor die vloedgolf van die swart nasionalisme staande gebly. Van hulle is daar wat nog in sekere sin onder koloniale beheer staan (soos byvoorbeeld die Portugese provinsies en Rhodesië), maar Suid-Afrika is een van die eerste lande wat hom geleidelik van kolonialistiese oorheersing bevry het, en wat met reg kan aanspraak maak dat hy ' $n$ vrye Afrikaland is in sy eie reg, 'n land wat self die kolonialisme oorwin het net so goed soos Amerika.

Maar so sien die Pan-Afrikanisme dit nie. Vir hulle is Suid-Afrika 'n oorblyfsel en vrug van die kolonialisme, omdat hier die witman oor die swartman regeer. En juis daarom moet hy in sy huidige gedaante as hoogontwikkelde, beskaafde Westersgeoriënteerde witmansland verpletter word, en moet hy geen kans gegun word om sy eie swart mense te lei binne die raamwerk van 'n groter Suid-Afrika tot selfregering met die beleid van afsonderlike ontwikkeling nie. Vir hierdie houding is daar verskillende redes. Ons noem en bespreek hier net kortliks die belangrikstes:

\section{Die rassistiese grondslag van die Pan-Afrikanisme}

Een van die vroegste leiers van die Pan-Afrikanistiese beweging, dr. William du Bois, het reeds in 1919 geskrywe dat die Pan-Afrikanisme vir die Negers dieselfde betekenis het as die Zionisme vir die Jode, naamlik: „The centralisation of ace effort and the recognition of a racial fount". Die deurbraak in hierdie tyd by die ontwikkelde Negers (in Amerika) van die besef van die historiese posisie van die swartman as die verdrukte en veragte, die ,uitgeworpene" onder die rasse, bring dan reaksie in die vorm van 'n sterk verlange na Neger- 
solidariteit en 'n uitdagende aanvaarding van, en trots in, Negerwees en swartkleurigheid. Dit kom veral tot openbaring by die nuwe swart intelligentsia opgelei in Europa en Amerika, in die verheerliking van wat in die Franse gebiede bekend geword het as negritude (negerheid) en in die Engelse gebiede as die African personality. Dil openbaar hom ook in dikwels oordrewe aansprake op Negerkultuurprestasies in die verlede en veral in ' $n$ bittere wrewel teen die witman in Afrika, wat gesien word as die vergestalting van die swartman se vernedering en minderwaardigheid. Dit verklaar ook waarom daar in die politieke filosofie van die Pan-Afrikanisme geen plek is vir die idee van veelrassigheid in die regering van Afrikastate nie, of van die idee van partnership, soos dit geformuleer en toegepas is in die voormalige Federasie van Rhodesië en Njassaland, of selfs van 'n gekwalifiseerde algemene stemreg (stemreg vir almal gebaseer op grond van beskawing, eiendom en/of inkomste) soos op die oomblik in Rhodesië, wat binne afsienbare tyd tot 'n swart regering kan lei.

Wat dic Pan-Afrikanisme verlang is swart dominasie sonder meer. Reeds by die eerste vergadering van die All-African Peoples Organisation in Akkra in 1958 het o.a. dr. Nkruhmah en Tom Mboya die eis dat die swartman in Afrika moet regeer onomwonde gestel en bietjie later het byvoorbeeld die voormalige Nigeriese opposisieleier, Awolowo, die eis gestel dat "the black man shall be absolute and indisputed master in his own home (d.i. in Afrika) and shall enjov unaffected and unpatronising equality with the other races of the world" (Persverklaring van 28 Junie 1961). Daarna is hierdie eise met steeds groter heftigheid gestel in die menigvuldige konferensies van die reeds genoemde $A A P O$, die Afro-Asian Solidarity Conference, die Pan-African Movement for East, Central and Southern Africa (PAFMACSA), en in die vergaderings van sulke streeksorganisasies soos die Casablanca- en Monroviagroepe. Want by alle onderlinge verskille en naywer het hulle op hierdie een punt 'n eenheidsfront gevorm.

\section{Die ekonomiese motief}

Die rassemotief is egter nie die enigste element in die Pan-Afrikanistiese vete teen Suidelike Afrika - en teen SuidAfrika in die besonder - nie. Daar is nog die ekonomiese motief. In die tweede vergadering van die staatshoofde van 
die Organisasie vir Afrika-eenheid in 1964 het dr. Nkrumah byvoorbeeld gepleit dat Afrika moet verenig om, soos hy dit uitgedruk het: „ons minerale rykdomme in Suid-Afrika te herwin". Sy plan vir 'n program van snelle nywerheidsontwikkeling op Afrikaans-kontinentale skaal berus op die beheer van die minerale rykdomme en die bestaande nywerheidskomplekse van Katanga, Zambië en veral Suid-Afrika. Daarom is die eerste stadium van die plan die bevryding van die Kongo van die "Neo-kolonialisme” (d.i. van Belgiese en Amerikaanse ekonomiese invloed) en Suid-Afrika van apartheid. Met die hulp van die kapitaal verkry van hierdie gebiede - en veral van Suid-Afrika onder swart beheer - kan, so meen die voorstanders van hierdie gedagterigting, die res van Afrika ontwikkel, die rykdomme van die Sahara, sonder hulp van buite, ontgin, en die groot riviere ingespan word om die kontinent een van die rykstes in die wêreld te maak.

\section{Die vrees vir reaksie}

En dan is daar uiteindelik nog die byna wanhopige vrees by die nuwe Afrika-leiers dat dic mense in die verskillende Afrikastate ontnugter gaan raak met hulle onafhanklikheid wanneer die besef deurdring dat aan die hoë verwagtinge wat by hulle gewek is, nie voldoen kan word nie. Die haatveldtog teen Suid-Afrika dien as 'n handige middel om die gedagte van die nog steeds voortdurende armocde, onkunde en agterlikheid af te lei.

\section{Die O.A.E.}

Die eenheidsfront teen die deur blankes beheerde Suidelike Afrika, het organisatories sy beslag in Mei 1963 gekry met die stigting van die Organisasie vir Afrika-eenheid. Sedert sy stigting het hierdie liggaam die veldtog teen Suid-Afrika oorgeneem en gekoordineer. Hierdie veldtog word op 'n wêreldwye front gevoer en het soveel fasette dat in 'n kort lesing soos hierdie slegs die belangrikste net genoem kan word.

In die eerste plek kan die maatreëls genoem word wat min of meer direkte aksie van die georganiseerde Afrika-state teen Suid-Afrika behels. Reeds by sy stigtingsvergadering in Mei 1963 het die OAE die grondslae van hierdie tipe optrede neergelê: 
1. 'n Spesiale Fonds is gestig om die bevrydingsbeweging in Afrika te steun.

2. 'n Sogenaamde Bevrydingskomitee van 9 lande is gestig (met setel in Dar es Salaam) om die Fonds te administreer en die bevrydingsbewegings te help koördineer en te steun. Dit sluit in opleiding van "vryheidsvegters" in die tegniek van sabotasie en guerilla-oorlog, wat die eerste fase kan word van 'n direkte aanslag teen die land.

3. Alle ledestate van die Organisasie het opdrag ontvang om:

(a) Alle diplomatieke en konsulêre verhoudinge met SuidAfrika te verbreek.

(b) Alle handel met Suid-Afrika te beëindig.

(c) Oorvlug- en landingsregte aan Suid-Afrikaanse vliegtuie te weier.

(d) Hulle hawens te sluit vir Suid-Afrikaanse skepe.

Hierdie program is in volle aksie teen Suid-Afrika en tot 'n mate ook teen die ander deur blankes beheerde state in Suidelike Afrika, naamlik Angola, Mosambiek en Rhodesië, wat fisies ook die bufferstate van Suid-Afrika vorm. Vir SuidAfrika skep hierdie maatreëls ongetwyfeld 'n mate van ongerief, en dit verhinder hom om sy regmatige aandeel te neem aan die ontwikkeling van Afrika, maar as faktor om die blanke beheer van die land tot ' $n$ val te bring, is dit van weinig betekenis. Dit verstewig inteendeel die wil van die blankes om die land en sy beskawing te beskerm teen die aanslae van swart Afrika. Die Pan-Afrikaniste besef dit en daarop spits hulle hul meer en meer toe op die mobilisering van die wêreldmening teen Suid-Afrika en op hulle pogings om die wêreldorganisasie, die V.V., te oorreed of te dwing tot kollektiewe optrede teen Suid-Afrika. Vir hierdie doel is die politieke klimaat van die wêreld vir hulle uiters gunstig. Nie alleen bied die "Koue Oorlog” tussen die kapitalistiese Weste en die Kommunistiese Ooste 'n gunstige situasie vir politieke (en ekonomiese) afpersing nie, maar in die nivelleringsfilosofie van beide die Kommunisme en die oorheersendsterke neoliberalistiese vleuel van clie Weste vind hulle 'n gewillige en gretige bondgenoot teen Suid-Afrika se beleid van rasseskeiding.

\section{Sielkundige "Kove Oorlog"}

Die kernmetode van hierdie breëre veldtog is om, met 
gebruikmaking van skewe en verwronge beriggewing en voorstellinge, Suid-Afrika se beleid voor te dra as 'n stelsel van ondraaglike onderdrukking en krenking van die menslike waardigheid, en om Suid-Afrika so tot skande en smaad in die wêreld te maak, die paria, die uitgeworpene, onder die nasies.

Op hierdie grondslag voly dan die stelselmatige poginge om Suid-Afrika op alle terreine van die internasionale samelewing te isoleer. Stelselmatig word ons land se stem gesmoor in sulke liggame soos:

Die Komitee vir Tegniese Samewerking in Afrika (CCTA).

Die Wetenskaplike Raad vir Afrika (CSA).

Die Wêreld-Gesondheidsorganisasie (WHO).

Die V.V. se Voedsel- en Landbou-organisasie (FAO).

Die V.V. se Ekonomiese Kommissie vir Alrika (ECA).

Die Internasionale Telekommunikasie-Unie (ITU).

Ook op die terreine van die kultuur en van sport word poginge aangewend - met ' $n$ mate van sukses - om SuidAfrika te isoleer.

Dit alles vorm deel van ' $n$ goedbeplande en volgehoue sielkundige "kouc oorlog" teen Suid-Afrika, aangevul deur pogings om die landsbestuur van binne te rysmier. Vir hierdie doel word veral gebruik gemaak van dic universiteite, die kerke en van allerlei maniere om jong mense, die toekomstige leiers, te beïnvloed. Afgesien van subtiele pogings om blanke jeugdiges en indiwiduele jong geleerdes na die buiteland te nooi en te beïnvloed, word ook fondse beskikbaar gestel vir opleiding van nie-blanke studente in die buiteland. Onlangs het mnr. Mennen Williams bckend gemaak dat ongeveer 200 nie-blanke studente uit Suidelike Afrika in Amerika studeer, gehelp deur 'n Amerikaanse ,educational program for young African refugee students", met die oogmerk ,to provide intelligent and democratic leadership to their people". Op die oomblik word ook 'n fonds deur die V.V. georganiseer om universiteitsopleiding aan Suid-Afrikaanse nie-blanke studente te verskaf, wat dan van hierdie voorreg in hulle eie land verstoke sou wees.

\section{Dwangmaatroëls}

In die nou reeds berugte publikasie van die Carnegie Endowment for International Peace (Apartheid and United 
Nations Collective Measures) skryf mej. Amelia C. Leiss: „Having failed to influence the South African leaders with mobilized opposition and approbrium, many members ol the United Nations... urge that the time has come for action of a different sort... South Africa... must be forced to alter its course."

Die baie lede waarvan hier sprake is, is die Afro-Asiatiese groep in die V.V. gesteun deur hulle Kommunistiese en neoliberalistiese vriende. Hulle dring met steeds groter heftigheid aan op kollektiewe duangmaatreëls teen Suid-Afrika. Paragraaf 7 van Artikel 2 van die V.V.-Oktrooi ontsê egter aan dié liggaam die reg om in te meng in die huishoudelike sake van ledestate, en daar is baie state wat vrees dat ' $n$ verbreking van dié reël as 'n boemerang kan werk en hulle eie veiligheid in gevaar kan stel.

Hoofstuk VIII, Artikel 39, van die Oktrooi verleen egter wel aan die V.V. die bevoegdheid om in te meng wanneer die optrede van enige staat die wêreldvrede in gevaar stel. Die Artikel lui:

„The Security Council shall determine the existence of any threat to the peace, break of the peace, or act of aggression and shall make recommendations, or decide what measures shall be taken in accordance with articles 41 and 42 , to maintain or restore international peace and security."

Artikel 41 maak voorsiening vir stappe wat gedoen kan word teen 'n staat wat die vrede in gevaar stel, o.a.:

,a complete or partial interruption of economic relations and of rail, sea, air, postal, telegraphic, radio, and other means of communication, and the severance of diplomatic relations";

en artikel 42 bepaal as sodanige stappe nie die gewenste uitwerking het nie, dan kan ander maatreëls toegepas word:

„Such action may include demonstrations, blockade, and other operations by air, sea, or land forces of Members of the United Nations."

As gevolg van hierdie omstandighede is die neiging by die Afro-Asiatiese groep en hulle vriende sedert 1960 om die Suid-Afrikaanse beleid as ' $n$ bedreiging van die wêreldvrede voor te stel.

Die tyd laat my nie toe om die veldtog teen Suid-Afrika in 
die V.V. ook maar eniger mate in besonderhede na te gaan nie. Alleen op 'n paar hoofmomente kan gelet word:

1. Sedert 1946 word die sogenaamde rassebeleid van SuidAfrika nagenoeg jaarliks in die V.V. opgehaal. Voor 1952 gaan dit, op inisiatief van Indië, hoofsaaklik oor die posisie van die Indiërs in Suid-Afrika, en owerigens oor die pogings om Suidwes-Afrika onder V.V.-voogdyskap te bring.

2. Na 1952 kom die breëre aspekte van die apartheidsbeleid onder die aandag van die V.V. op aansporing van die Asiatiese lede, en in 1954 word vir die eerste keer 'n nuwe geluid gehoor toe besluit is dat ,the policy of apartheid constitutes a grave threat to the peaceful relations between the ethnic groups in the world".

3. Na 1960, toe baie nuwe Afrikastate lid van die V.V. geword het, word die aandrang op kollektiewe dwangmaatreëls teen Suid-Afrika steeds sterker. In 1961 word die aandag van die Veiligheidsraad deur die Algemene Vergadering gevestig op paragraaf 3 van Artikel 11 van die V.V.-Oktrooi waarvolgens ,the General Assembly may call the attention of the Security Council to situations which are likely to endanger international peace and security", en op 6 November 1962 besluit die Algemene Vergadering om ledestate te versoek om:

(a) Diplomatieke verhouding met Suid-Afrika te verbreek.

(b) Hulle hawens vir Suid-Afrikaanse skepe te sluit.

(c) Wetgewing aan te neem wat hulle skepe verbied om Suid-Afrikaanse hawens binne te vaar.

(d) Alle Suid-Afrikaanse goedere te boikot en niks (insluitende wapens en ammunisie) na Suid-Afrika uit te voer nie.

(e) Landingsregte vir alle Suid-Afrikaanse vliegtuie te weier.

\section{Veiligheidsraad benoem 'n komitee van deskundiges}

Dit is egter een saak om dergelike maatreëls by ledestate aan te beveel en 'n heeltemal ander saak om sulke maatreëls as kollektiewe dwangmaatreëls toe te pas, veral waar soveel van die belangrike state handelsbetrekkinge met SuidAfrika onderhou en groot belang het in die skeeps- en lugverkeer met Suid-Afrika. Die Veiligheidsraad het derhalwe in Junie 1964 besluit om 'n Komitee van Deskundiges aan te stel insake die uitvoerbaarheid, doeltreffendheid en implikasies van maatreëls wat deur die Veiligheidsraad teen SuidAfrika onder die V.V.-Oktrooi getref kan word. 
Hierdie Komitee, waarvan die sittings konsekwent deur een van sy lede, naamlik Frankryk geboikot is, het as sy mening uitgespreek dat „South Africa's economy would be susceptible to the effects of a total blocking of trade... and to an interdiction of communications".

Hulle was owerigens van mening dat 'n embargo op petrol en petroleum-produkte baie effektief sou wees en dat 'n beëindiging van emigrasie na Suid-Afrika (tegnici) en van finansiële transaksies met Suid-Afrika nuttig sou wees.

Hierdie maatreëls, meen hulle, was uitvoerbaar, maar die doeltreffendheid daarvan sou afhang van die mate van eenstemmigheid van die ledestate, veral dié wat belangrike ekonomiese betrekkinge met Suid-Afrika handhaaf, om saam te werk. Baie sou ook afhang van die ekonomiese krag van Suid-Afrika om die uitwerking van die voorgestelde maatreëls te weerstaan en van die wil van die volk van Suid-Afrika om hulle daarteen te verset.

So staan sake dan op die oomblik. Die Spesiale Komitee insake Apartheid van die Algemene Vergadering gaan voort om druk uit te oefen vir die tuepassing van dwangmaatreëls, onderwyl die veldtog teen Suid-Afrika deur die Afrikastate en in die V.V. en sy komitees, sowel as op baie ander terreine, met steeds toenemende heftigheid gevoer word. Volgehoue pogings word aangewend deur die Afrikastate en die neo-liberaliste in die Weste om die openbare mening, veral in Brittanje en die V.S.A., te beïnvloed ten gunste van deelname aan sanksies teen Suid-Afrika, omdat hierdie lande - en veral Brittanje - self swaar getref kan word deur sulke maatreëls; en omdat sonder hulle volle medewerking die vooruitsigte op sukses maar gering is.

Die vyande van Suid-Afrika vestig nou hulle hoop op 'n vir Suid-Afrika - ongunstige uitspraak van die Wêreldhof in die geding oor Suidwes-Afrika. Dit, meen hulle, kan uiteindelik aanleiding gee tot die toepassing van sanksies teen 'n halsstarrige Suid-Afrikaanse Regering, gepaard met 'n blokkade teen Suid-Afrika en moontlike binnelandse onluste, wat weer op hulle beurt aanleiding kan gee tot gewapende inmenging deur die V.V., gesteun deur die grootmoontdhede. Die moontlike verloop van sake, die vloot-, lug- en landmagte daarvoor benodig en die potensiële koste aan die operasie verbonde, is onlangs nog in Amerika onder die patronaat van die Carnegie Endowment for International Peace, haarfyn uitge- 
werk. In hierdie selfde dokument word die stelling neergelê dat sake nou so ver gevorder het dat nie slegs die lot van Suid-Afrika nie, maar veral ook dié van die Verenigde Volke by die uitslag van die stryd op die spel is.

Of van die grootmoonclhede in die V.V. die nodige eensgesindheid sal kan bereik om oor te gaan tot die toepassing van ekonomiese, maar veral militêre dwangmaatreëls, teen Suid-Afrika val te betwyfel. Dic moontlikheid daarvan kan egter nie uitgesluit word nie. Indien dit wel gebeur, sal die uitslag afhang van wêreldomstandighede, maar veral van die ekonomiese weerstandskrag van Suid-Afrika, die eensgesindheid van sy mense en hulle vermoë om uit te hou te midde van ongerief en moontlike gebrek, en hulle wil om weerstand te bied, wel wetende dat dit wat hulle gedurende drie eeue opgebou het - en selfs huis en haard - op die spel is.

Pretoria.

A. J. H. van der Walt. 